\title{
Neurogenesis-enhancing effect of sodium ferulate and its role in repair following stress-induced neuronal damage
}

\author{
Lijian Yu ${ }^{1 *}$, Yongping Zhang ${ }^{1}$, Mingneng Liao ${ }^{1}$, Yanping Wang ${ }^{1}$, Rundi Ma ${ }^{1}$, Xiaoyu Zhang ${ }^{1,2}$, Tingxi Yu ${ }^{1,3^{*}}$ \\ ${ }^{1}$ Key Laboratory of Marine Materia Medica, Guangdong Ocean University, Zhanjiang, China; \\ ${ }^{2}$ Department of Otorhinolaryngology-Head and Neck Surgery, University of Maryland School of Medicine, Baltimore, USA; \\ ${ }^{3}$ Cell Biology Group, Department of Surgery, Department of Pathology, University of Maryland School of Medicine and Baltimore \\ Veterans Affairs Medical Center, Baltimore, USA. \\ Email: *yutingxi@yahoo.com, ${ }^{*}$ ywyj9578@sohu.com
}

Received 22 April 2011; revised 11 May 2011; accepted 18 June 2011.

\section{ABSTRACT}

Ferulic acid (FA) is a ubiquitous phenolic acid of low toxicity, and sodium ferulate (SF) is its sodium salt. Our previous studies have revealed that FA shows neuroprotective effect and significant antidepressantlike effect. The aim of this study was to investigate its potential neurogenesis-enhancing effect and its role in repair following stress-induced neuronal damage. MTT assay was performed to measure the effect of SF on the growth of rat pheochromocytoma (PC12) cells; morphological and immunocytochemical methods were used for assessing its differentiation-inducing action. Chronic mild stress (CMS) tests were performed to establish rat model of depression. The histopathology of animal brains was studied to analyze CMS-induced morphological changes and the effect of SF on the repair of CMS-induced brain injury. The expressions of nerve growth factor (NGF) and brain-derived neurotrophic factor (BDNF) and the proliferation of neural stem cell/neural progenitor cells were assessed in the hippocampi of chronic mild stress (CMS)-induced depression-like model rats by immunohistochemistry and bromodeoxyuridine (BrdU)incorporation assays, respectively. Our in vitro tests showed that SF promoted the proliferation of PC12 cells in the concentration range of $5-320 \mu \mathrm{M}$, and induced PC12 cells to differentiate to more mature cells with the morphological characteristics and molecular marker of neuronal-like cells. In vivo tests showed that SF up-regulated the expressions of NGF and BDNF, and induced the proliferation of neural stem cell/neural progenitor cells in the hippocampi of CMS-induced depression-like model rats. This study provides evidences that SF shows neurogenesis-enhancing effect, and its antidepressant-like effect of SF may be related directly and closely to its above-men- tioned effect.

Keywords: Sodium Ferulate; Neurogenesis-Enhancing Effect; Rat Pheochromocytoma (PC12) Cells; Stressinduced Neuronal Damage

\section{INTRODUCTION}

Today, preclinical and clinical investigations have shown the involvement of dysregulation of hypothalamic-pituitary-adrenal (HPA) axis in the pathogenesis of depression. Excessive release of glucocorticoid is closely related to the hippocampus atrophy. Hypercortisolemia and the associated hippocampal atrophy were observed in patients with depression, which could be ameliorated by the treatment with antidepressants [1]. Moreover, the volumes of the double-side hippocampus were reduced in the major depressive patients compared to the healthy control and there was a positive correlation between the hippocampus atrophy and the time course of the depresssion [2,3]. Consequently, it is reasonable that, in some cases, psychopathology arises as a consequence of altered morphological structure of particular brain. There is growing evidence that adult animals continue to produce new neurons in the dentate gyrus of hippocampus; neurogenesis in the adult dentate gyrus has been observed in all mammalian species examined to date, including humans [4]; stress causes a decrease of neurogenesis in the dentate gyrus; and antidepressant treatment in turn stimulates the cell proliferation in the dentate gyrus. Furthermore, the waning and waxing of neurogenesis in brain areas such as the dentate gyrus is proposed as a key factor in the descent into and recovery from clinical depression, respectively, and a decrease in neurogenesis could occur due to genetic factors and stress (especially because of the involvement of adrenal corticoids) [5].

Ferulic acid (FA), 3-(4-hydroxy-3-methoxyphenyl)-2- 
propenoic acid (Figure 1(a)), is one of the most common phenolic acids with low toxicity [6]. FA is waterinsoluble, but its sodium salt, sodium ferulate (SF) (Figure 1(b)), is water-soluble, stable, and can be prepared by chemical synthesis [7]. FA shows a lot of biological activities, including antioxidant $[8,9]$ ), anti-inflammatory $[10,11]$, and hypotensive effect $[12,13]$.

Our previous work demonstrates that SF shows obvious neuro-protective effect [14]. The simultaneous administration of SF with monosodium glutamate (MSG) reverses the effects of MSG on behavior and histopathology in mice [15-17]; intracerebroventricularly administered SF mediates brain repair following MSGinduced exitotoxic neuronal damage in adult mice [18, 19]; and administration of SF also shows antidepressantlike effects in animal models of depression [14]. Therefore, it is interesting and reasonable to further investigate the neurogenesis-enhancing effect of SF in vitro and in vivo and to discuss their relationship with its antidepressant-like effects.

\section{MATERIALS AND METHODS}

\subsection{Drugs and Chemicals}

SF was purchased from Yaoyou Pharmaceutic Co. Ltd (Chongqing, China); fluoxetine (FLU) hydrochloride purchased from Eli Lilly and Company Limited (USA). Mouse anti-neuronfilament-200 (NF-200) monoclonal body was purchased from Wuhan Boster Biological Technology LTD (China), and TRICH-anti-mouse IgG purchased from Beijing Zhong Shan-Golden Bridge Biological Technology Co. LTD (China). Rabbit anti-rat polyclonal antibodies (anti-NGF and anti-BDNF) were purchased from Beijing Boisynthesis Biotechnology LTD (Beijing, China). 5-Bromo-2'-deoxyuridine (BrdU) was purchased from Roche Diagnostics GmbH (Boehringer-Mannheim, Indianapolis, IN), and rat anti-BrdU monoclonal antibody purchased from Abcam (Hong Kong) Ltd. Biotinyllated horse anti-mouse antibody, avidin-biotin complex were purchased from Beijing
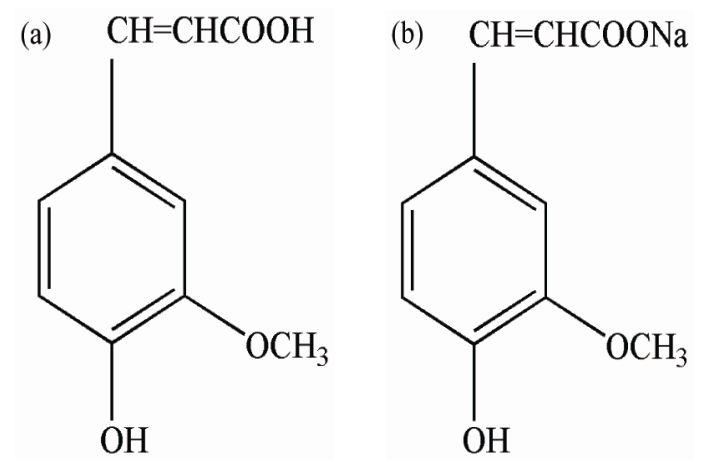

Figure 1. Chemical structure of ferulic acid (a) and sodium ferulate (b).
Biosynthesis Biotechnology Co. (China). DAB substrat kit was purchased from Invitrogen corporation. Dulbecco's Modified Eagle Medium (DMEM) and 3-(4,5-dimethylthiazol-2-yl)-2,5-diphenyltetrazolium bromide (MTT) were purchased from Sigma Chemical Co.. NCS was obtained from Sijiqing Biological Material Co. (Hangzhou, China). Horse serum was purchased from Hyclone. All other chemicals used were of reagent grade.

\subsection{Cell Line and Cell Culture}

A clonal cell line derived from a pheochromocytoma (PC12) of the rat adrenal medulla [20] was purchased from Shanghai Institute of Biochemistry and Cell Biology, Chinese Academy of Sciences. Cells were grown in DMEM supplemented with $10 \%$ newborn calf serum (NCS), 5\% horse serum and antibiotics (100 units $/ \mathrm{ml}$ penicillin, $100 \mu \mathrm{g} / \mathrm{ml}$ streptomycin) in flasks precoated with collagen [21]. The culture was replaced after 2 months of passage by thawing a fresh aliquot of frozen cells. The culture were maintained in a humidified atmosphere containing $5 \% \mathrm{CO}_{2}$ at $37^{\circ} \mathrm{C}$. Cells in log phase growth were used in the experiments.

\subsection{Animals}

Adult male Sprague-Dawley (SD) strain rats weighing 220 - $280 \mathrm{~g}$ (specific pathogen free) purchased from the experimental animal center of Guangdong Medical College (experimental animal license SCXKyue 2007-2008 A034, No.0001909; Zhanjiang, China), were used across all the experiments. They had free access to tap water and standard laboratory food unless otherwise stated. Housing conditions were controlled, temperature was maintained at $22^{\circ} \mathrm{C} \pm 1{ }^{\circ} \mathrm{C}$ with approximately $60 \%$ relative humidity. They were kept on a reversed 12/12 h light/dark cycle (light 07:00 - 19:00 h). Animals were acclimated to the animal quarters for 1 week before any experimental procedure. All the animals were treated in compliance with "Guidance Suggestions (Instructions) for the Care and Use of Laboratory Animals" Issued on September 30, 2006 by The Ministry of Science and Technology of the People's Republic of China.

\subsection{MTT Assay}

The mitochondrial metabolism of MTT to its insoluble blue formazan was used for enumerating cells to assess the effects of SF, $\mathrm{H}_{2} \mathrm{O}_{2}$, and glucocorticoid on the growth of PC12 cells and the protective effects of SF against oxidative damage and glucocorticoid-induced neurotoxicity according to the methods of Hansen et al. [22]. Briefly, Single-cell suspensions were prepared and seeded onto 96 well microculture plates at $1.0 \times 10^{5}$ cells $/ \mathrm{ml}(90$ $\mu \mathrm{l} /$ well). Cells were cultured for $12 \mathrm{~h}$ before addition of drugs. Drugs were diluted into DMEM and added to 
each well in a volume of $10 \mu$ l. Cells were incubated at $37^{\circ} \mathrm{C}$ for the time indicated. MTT solution $(5 \mathrm{mg} / \mathrm{ml})$ was aliquoted to each well in a volume of $20 \mu \mathrm{l}$, and $5 \mathrm{~h}$ later $100 \mu \mathrm{l}$ of the solubilization solution ( $10 \%$ SDS-5\% isobutyl alcohol-0.012 $\mathrm{M} \mathrm{HCl}(\mathrm{w} / \mathrm{v} / \mathrm{v}))$ was added into each well. The plates were allowed to stand overnight in the incubator in a humidified atmosphere. Absorbance at $570 \mathrm{~nm}$ was determined for each well using an ELISA reader. Control wells contained all of the agents presented in the treated wells except the drug(s). Each experimental point was performed in three replicates. Data were expressed as a percentage of untreated control cultures.

\subsection{Effect of SF on the Growth of PC12 Cells}

PC12 cells were cultured with different concentrations of SF for $24 \mathrm{~h}$. Cell viability was examined by MTT assay.

\subsection{Differentiation Induction of PC12 Cells}

PC12 cells were cultured in DMEM with SF for the time indicated, and the effects of different concentrations (10 $\mu \mathrm{M}, 20 \mu \mathrm{M}, 40 \mu \mathrm{M}, 80 \mu \mathrm{M}, 160 \mu \mathrm{M})$ of SF on morphological and molecular changes were investigated at different time points in $\mathrm{PC} 12$ cells. Cells were analyzed throughout the differentiation process $(6 \mathrm{~h}$ and 1, 2, 3, 4, $5,6,7,8$, and 9 days), for neurite outgrowth, and for molecular marker NF-200.

For neurite outgrowth, visual fields of $1 \mathrm{~cm}^{2}$ were randomly selected in each dish of SF-induced differentiated PC12 cells. Photographed images were generated for all fields at each time point ( $6 \mathrm{~h}$ and 1, 2, 3, 4, 5, 6, 7, 8 , and 9 days) using Leica DM IRB photomicroscope [23].

For molecular marker NF-200 [24], the cells were submitted to the immunocytochemistry of the NF-200 $[25,26]$ on the 7 th day. Briefly, cells in the wells of the 24-wells plates were washed with PBS. Cells then were fixed at room temperature for $30 \mathrm{~min}$. Nonspecific binding sites were blocked with $5 \%$ NCS, $5 \%$ goat serum and $0.5 \%$ triton X-100 all in PBS for 1 hour. The primary antibody was added to the cells after being appropriately diluted in PBS and incubated overnight at $+4^{\circ} \mathrm{C}$. $0.01 \mathrm{M}$ PBS was added to the cells in control group instead of the primary antibody. Cells were washed with PBS 3 times for 10 minutes and the secondary antibodies were added after being appropriately diluted in PBS and left for one hour at room temperature. After adding the second secondary antibodiy for $1 \mathrm{~h}$, cells were washed again in PBS 3 times for 10 minutes. Slides were stored in dark at $4^{\circ} \mathrm{C}$. Slides were later visualized using Leica inverted confocal microscope and Zeiss laser confocal microscope.

\subsection{CMS Procedures}

The animals were assigned randomly into six matched groups ( $n=12$ animals in each group) based on sucrose consumption ( $1 \%$ sucrose solution) before onset of CMS: control, CMS, fluoxetine control (CMS + FLU), CMS + $\mathrm{SF}(10,20,40 \mathrm{mg} / \mathrm{kg} / \mathrm{d})$ groups. The stressed rats were ex- posed to CMS for 28 days; The rats in CMS + FLU group were exposed to CMS and received administration of FLU $(2.0 \mathrm{mg} / \mathrm{kg} / \mathrm{d}$, ig, once-daily) for 28 days; the rats in CMS + SF groups were exposed to CMS and received administration of $\mathrm{SF}(10,20,40 \mathrm{mg} / \mathrm{kg} / \mathrm{d}$, ip, once-daily) respectively for 28 days. The control rats were given ordinary daily care and received ip administration of normal saline instead of SF and FLU, for 28 days. The stressed and control rats were kept in different rooms to allow independent manipulation of their environments during the duration of the stress procedure. Control rats were housed together, while the stressed rats were housed singly.

Most of the stressors were adapted from the procedure described by Willner and collaborators [27] and some stressors were included from Moreau and collaborators (e.g. empty water bottle, restricted food) [28]. Each week included $2 \mathrm{~h}$ of paired caging, $3 \mathrm{~h}$ of tilted cage (45 degrees), $18 \mathrm{~h}$ of food deprivation immediately followed by $1 \mathrm{~h}$ of restricted access to food ( 5 micropellets), $2 \times$ $18 \mathrm{~h}$ of water deprivation immediately followed by $1 \mathrm{~h}$ exposure to an empty bottle, $21 \mathrm{~h}$ of wet cage $(200 \mathrm{ml}$ water in $100 \mathrm{~g}$ sawdust bedding), and $36 \mathrm{~h}$ of continuous light. Stressors were presented both during the rats' active (dark) period and during the inactive (light) period. The same stressors were used in all experiments.

\subsection{Immunohistochemistry}

NGF and BDNF levels. For in vivo analysis of NGF and BDNF levels, the whole brains of 4 unselected rat were dissected and removed 2 days after the last antidepressant treatment and inmediately fixed in $10 \%$ formalin in $0.1 \mathrm{M}$ PBS (pH 7.4) at $4^{\circ} \mathrm{C}$ for 2 days, and processed by paraffin embedding methods. Sections $4 \mu \mathrm{m}$ thick were cut and processed for inmunohistochemistry. The immunohistochemistry of NGF and BDNF on sections was performed using a streptavidin-peroxidase conjugate (SP) method according to the manufacturer's instructions [29, 30]. Primary antibodies (see Chemicals) were diluted 1: 100. After incubation of primary antibodies at room temperature overnight, the sections were incubated with second antibodies $15 \mathrm{~min}$ at room temperature, and the reaction was visualized with $\mathrm{DAB}$. Controls were made according to the same procedure, but omitting the primary antibody.

Sections obtained were matched for comparable hip- 
pocampal level. Brain regions were identified via a light microscope. Rabbit anti-rat polyclonal antibody (antiNGF and anti-BDNF) labels were identified by the characteristic yellowish brown stain seen in NGF and BDNF positive cell bodies. Changes in the number of immunopositive cells of the hippocampal DG sector in stained sections were counted under a light microscope at a magnification of $\mathrm{a} \times 200$ without the examiner knowing the experimental protocols, and the average of five different areas was determined. All values were expressed as the means \pm SEM and statistical significance was evaluated by Dunnet's multiple comparison test fornonparametric analysis.

\subsection{In Vivo BrdU-Incorporation Assay}

For in vivo BrdU-incorporation assay [31], rats were administered BrdU ( $4 \times 75 \mathrm{mg} / \mathrm{kg}$ every $2 \mathrm{~h}$; Sigma, St. Louis, MO) 4 days after the last antidepressant treatment. The 4 days time point was chosen because a similar paradigm has been used in a previous study of chemicalinduced seizures on hippocampal neurogenesis [32]. Twenty-four hours after the last BrdU injection, rats were killed and transcardially perfused $(0.1 \mathrm{M}$ cold PBS for $5 \mathrm{~min}$ followed by 4\% cold paraformaldehyde for 17 min). After perfusion, all brains were post-fixed overnight in paraformaldehyde (with shaking) at $4^{\circ} \mathrm{C}$ and stored at $4^{\circ} \mathrm{C}$ in $30 \%$ sucrose. Serial sections of the brains were cut $(35 \mathrm{~mm}$ sections through the entire hippocampus [33] on a freezing microtome, and sections were stored in $\mathrm{PBS} / \mathrm{NaN}_{3}$.

Free-floating sections were used in the determination of BrdU labeling. DNA denaturation was conducted by incubation for $2 \mathrm{~h}$ in $50 \%$ formamide $/ 2 \times \mathrm{SSC}$ at $65^{\circ} \mathrm{C}$, followed by several PBS rinses. Sections were then incubated for $30 \mathrm{~min}$ in $2 \mathrm{~N} \mathrm{HCl}$ and then 10 min in $\mathrm{H}_{2} \mathrm{O}_{2}$ to eliminate endogenous peroxidases. After blocking with $3 \%$ normal horse serum in $0.01 \%$, triton X-100, cells were incubated with anti-rat $\operatorname{BrdU}(1: 1000)$ over night at $4^{\circ} \mathrm{C}$. Sections were then incubated for $1 \mathrm{~h}$ with secondary antibody (biotinylatedhorseanti-mouse) followed by amplification with an avidin-biotin complex and cells were visualized with DAB.

Sections obtained were matched for comparable hippocampal level. Brain regions were identified via a light microscope. Anti-BrdU labels were identified by the characteristic yellowish brown stain seen in BrdU-positive cell bodies. Changes in the number of immunopositive cells of the hippocampal CA3 sector in stained sections were counted under a light microscope at a magnification of $\mathrm{a} \times 200$ without the examiner knowing the experimental protocols, and the average of five different areas was determined. All values were expressed as the means \pm SEM and statistical significance was evaluated by Dunnet's multiple comparison tests for nonparametric analysis.

\subsection{Statistical Analysis}

Values are expressed as the means \pm SEM. Data were analyzed with SPSS 10.0 software. A probability of $p<$ 0.05 was considered significant.

\section{RESULTS}

\subsection{Promotion Effect of SF on the Proliferation of PC12 Cells}

PC12 cells were cultured with different concentrations of SF for 24 h. Figure 2 showed the concentration-dependent promotion effect of cell proliferation by SF. At concentrations higher than $5 \mu \mathrm{M}$, the cell proliferation climbed up slowly, and SF showed significantly promotion effect on the cell proliferation at those from 80 to $320 \mu \mathrm{M}$.

PC12 cells were cultured with different concentrations of SF for $24 \mathrm{~h}$. Cell viability was examined by MTT assay. The data of one representative experiment from three independent experiments were expressed as mean \pm SEM $(n=4) .{ }^{*} P<0.05,{ }^{* *} P<0.01$ as compared with control (without SF).

\subsection{Induction of PC12 Cell Differentiation by SF}

In order to study the effect of SF on PC12 cell differentiation, PC12 cells were treated without or with SF (10$160 \mu \mathrm{M})$. There was significant neurite length growth in the $160 \mu \mathrm{M}$ SF-supplemented group on the 3rd day, in the $80 \mu \mathrm{M}$ SF-supplemented group on the 4th day, and in the $40 \mu \mathrm{M}$ SF-supplemented group on the 7 th day. The SF-supplemented cells showed significantly accelerated neurite outgrowth compared to the control cells (Figure 3(A-B)). The cells acquired advanced neuronal phenotypes with long axons structures connecting cells to each other formed potential complex neural networks (Figures $\mathbf{3 A}(\mathbf{c})$ and $\mathbf{B}(\mathbf{b}-\mathbf{c})$ ).

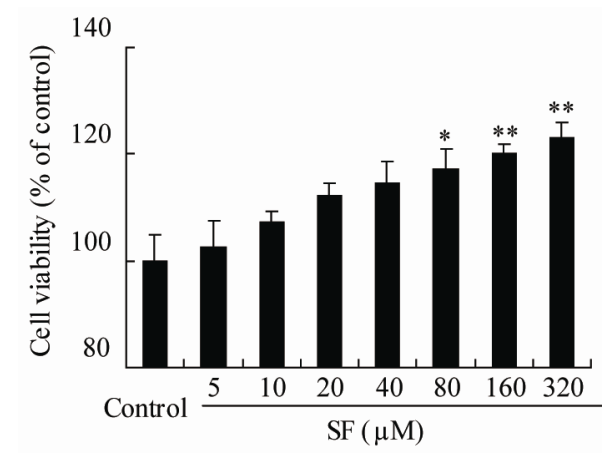

Figure 2. Effect of SF on the cell viability in PC12 cells. 

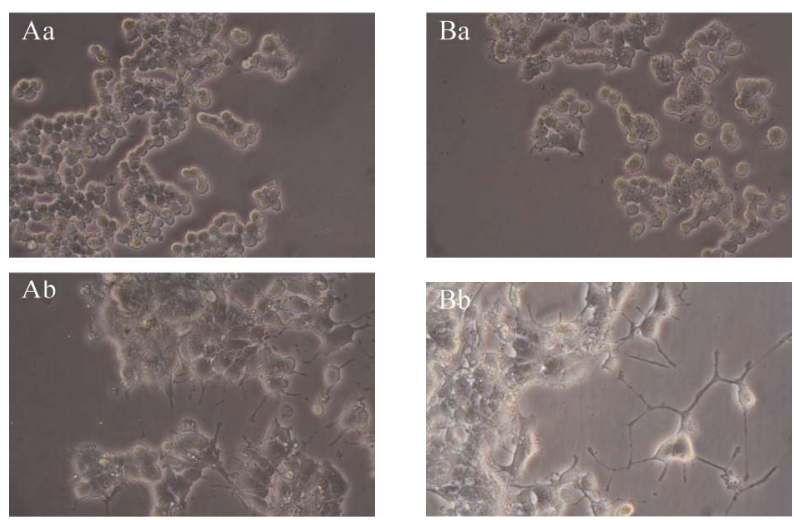

Figure 3. Neurite outgrowth in the presence of SF.

PC12-cells were grown in the absence (control) or presence of SF $(80,160$ $\mu \mathrm{M})$. Neurite outgrowth was monitored for 9 days, starting $6 \mathrm{~h}$ post-supplementation of SF. Representative micrographs of PC12-cell culture are shown $(\times 200)$. A. $4^{\text {rd }}$ day: a. control, b. $80 \mu \mathrm{M}$, c. $160 \mu \mathrm{M} ;$ B. $7^{\text {th }}$ day: a. control, b. $80 \mu \mathrm{M}$, c. $160 \mu \mathrm{M}$.

To determine whether the PC12 cells can synaptically integrate and mature in the culture with SF, we examined the expression of NF-200, marker of neuronal differentiation. After 3 - 4 days of incubation cells lost their perfect round shape and small projections start to grow from these cells. After a week of differentiation in the presence of SF, cells showed polar morphology, axons and dendrites structures were clearly noticed and potential simple neural network was noticed (Figures 3A(c) and $\mathbf{B}(\mathbf{b}-\mathbf{c})$ ). The differentiation process was accompanied with apoptosis of some differentiation cells. The differentiating cells formed a much complex potential neural networks (Figure 4(c-d)). NF-200 (Red) highly expressed and was highly concentrated along the axon structures of the neuronal cells (Figure 4(d)). Staining with anti-NF-200 antibody showed that NF-200 expression was evident and PC12 cells underwent a process of maturation.

The results revealed that under the action of SF, PC12 cells could be induced to differentiate to more mature cells with the morphological characteristics and molecular marker of neuronal-like cells.

\subsection{Protective Effect of SF against CMS-Induced Reduction of Hippocampal NGF and BDNF Levels}

Hippocampal NGF and BDNF levels were obviously reduced in the CMS mice (Figures 5A(a-b) and $\mathbf{B}(\mathbf{a}-\mathbf{b})$ ). In contrast, $\mathrm{SF}$ treatment reversed the effects of CMS on the hippocampal NGF and BDNF levels in a dose-dependent manner (Figures 5A(a, d, e, f) and B(a, d, e, f)), and the effect of $\operatorname{SF}(40 \mathrm{mg} / \mathrm{kg} / \mathrm{d})$ was comparable with that of FLU $(2.0 \mathrm{mg} / \mathrm{kg} / \mathrm{d})$ control (Figures $5 A(c$, e, f) and $\mathbf{B}(\mathbf{c}, \mathbf{e}, \mathbf{f})$ ). Consequently, the results suggest that $\mathrm{SF}$

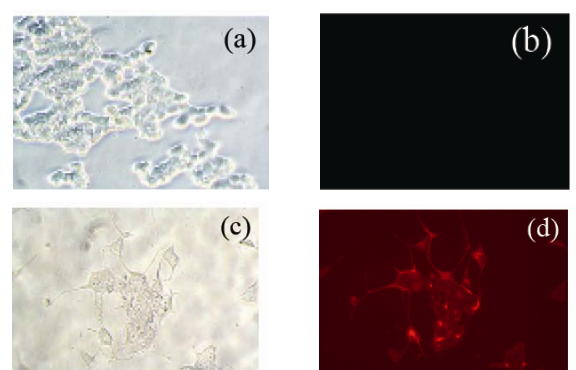

Figure 4. Neuronal-like differentiated and maturated cells $(\times 200)$.

PC12-cells were grown in the absence (control) or presence of SF $(80,160 \mu \mathrm{M})$ for 9 days. For molecular marker NF-200, the cells were submitted to the immunocytochemistry of the NF-200 on the 7th day as described in "Materials and methods". (a) control (b) control, using PBS instead of primary antibody (NF-200 monoclonal body); (c) PC12 cells treated with $160 \mu \mathrm{M}$ SF for 7 days. The cells acquired advanced neuronal-like phenotypes with long axons structures connecting cells to each other forming potential complex neural networks; (d) PC12 cells treated with $160 \mu \mathrm{M}$ SF for 7 days were submitted to the immunocytochemistry of the NF-200. The cells with neuronal-like morphology after differentiation and maturation highly expressed NF-200 (red).

treatment partially reverses the effects of CMS on hippocampal NGF and BDNF.

The whole brains of unselected rat $(n=4)$ were dissected and removed 2 days after the last antidepressant treatment and inmediately fixed in 10\% formalin, and processed by paraffin embedding methods. Sections 4 $\mu \mathrm{m}$ thick were cut and processed for inmunohistochemistry. The immunohistochemistry of NGF and BDNF on sections was performed using a streptavidin-peroxidase conjugate (SP) method according to the manufacturer's instructions. Rabbit anti-rat polyclonal antibody (antiNGF and anti-BDNF) labels were identified by the characteristic yellowish brown stain seen in NGF and BDNF positive cell bodies. Changes in the number of immunopositive cells of the hippocampal DG sector in stained sections were counted under a light microscope at a magnification of a $\times 200$, and the average of five different areas was determined. All values were expressed as the means \pm SEM, and statistical significance was evaluated by Dunnet's multiple comparison tests for nonparametric analysis.

\subsection{Protective Effect of SF against the \\ Reduction of Neurogenesis in the \\ Hippocampal CA3 Sector of \\ CMS-Induced Depression-Like Model Rats}

Analysis of the number of BrdU-labeled cells demonstrated that the number of BrdU-labeled cells was obviously reduced in the CA3 of CMS mice (Figure 6(a-b)). In contrast, long-term administration of SF $(10,20,40$ 

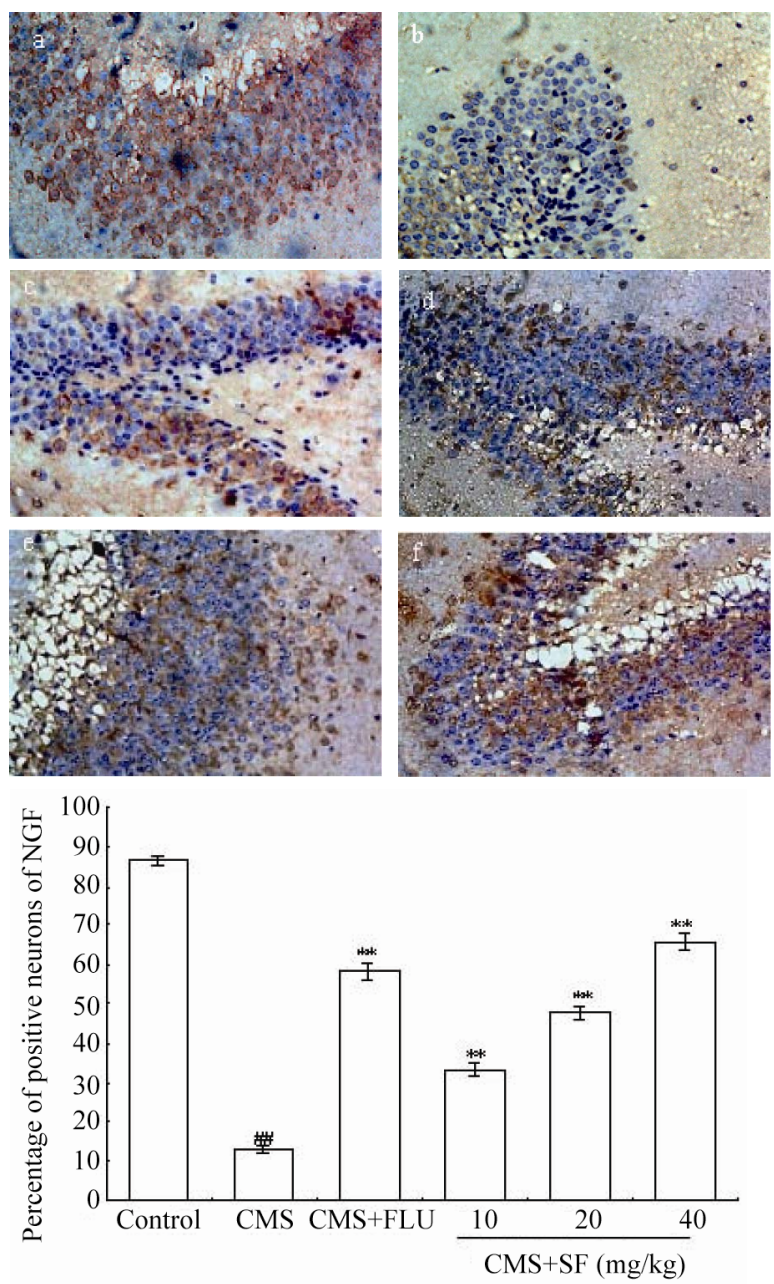

(A)
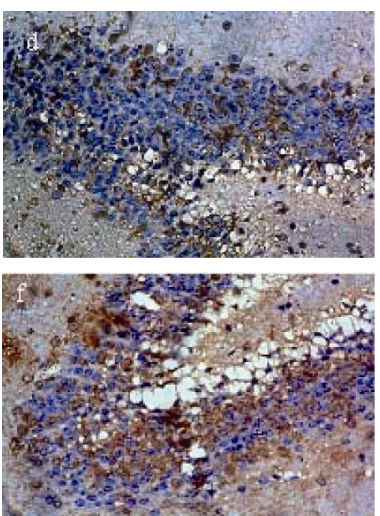
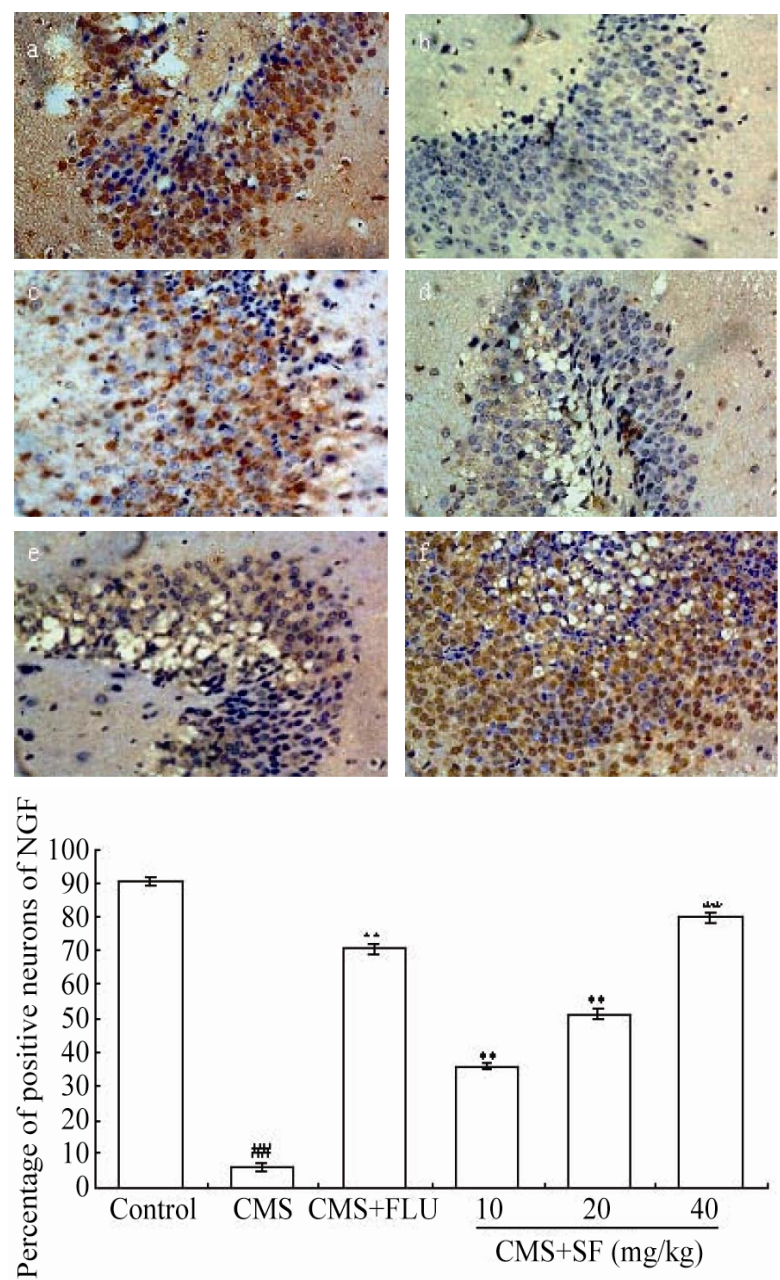

(B)

Figure 5. Representative microphotographs and numbers of NGF(A)- and BDNF(B)-immunopositive neurons in the hippocampal DG sector of CMS-induced depression-like model rats.

(A) Representative microphotographs and numbers of NGF-immunopositive neurons $(\times 200)$. a. Control; b. CMS; c. CMS + FLU (2.0 mg/kg); d. CMS $+\mathrm{SF}(10 \mathrm{mg} / \mathrm{kg})$; e. CMS + SF(20 mg/kg); f. CMS+; (B) Representative microphotographs and numbers of BDNF-immunopositive neurons $(\times 200)$. a. Control; b. CMS; c. CMS + FLU (2.0 mg/kg); d. CMS + SF(10 mg/kg); e. CMS + SF(20 mg/kg); f. CMS + SF(40 mg/kg).

$\mathrm{mg} / \mathrm{kg} / \mathrm{d})$ significantly increased the number of BrdUlabeled cells by $8.6 \%, 27.8 \%, 47.7 \%$ in the CA3 of CMS mice in a dose-dependent manner (Figure 6(b, d, e, f)), respectively, whereas FLU $(2.0 \mathrm{mg} / \mathrm{kg} / \mathrm{d})$ increased the BrdU labeling by $23.2 \%$ (Figure 6(b-c)). Consequently, the results suggest that SF treatment reverses partially the effects of CMS on the neurogenesis in the hippocampi of the rats, and the effects of $\mathrm{SF}(20,40 \mathrm{mg} / \mathrm{kg} / \mathrm{d})$ were comparable with that of FLU $(2.0 \mathrm{mg} / \mathrm{kg} / \mathrm{d})$ control.

For in vivo BrdU-incorporation assay, rats were administered $\operatorname{BrdU}(4 \times 75 \mathrm{mg} / \mathrm{kg}$ every $2 \mathrm{hr}) 4$ days after the last antidepressant treatment. Twenty-four $h$ after the last BrdU injection, rats were killed and transcardially perfused. After perfusion, all brains were post-fixed overnight in paraformaldehyde (with shaking) at $4^{\circ} \mathrm{C}$ and stored at $4^{\circ} \mathrm{C}$ in $30 \%$ sucrose. Immunohistochemistry assay was performed as "Materials and Methods". AntiBrdU labels were identified by the characteristic yellowish brown stain seen in BrdU-positive cell bodies. Changes in the number of immunopositive cells of the hippocampal CA3 sector in stained sections were counted under a light microscope at a magnification of a $\times 400$ without the examiner knowing the experimental protocols, and the average of five different areas was determined. All values were expressed as the means \pm SEM and statistical significance was evaluated by Dunnet's multiple comparison tests for nonparametric analysis.

\section{DISCUSSION}

Our previous investigations reveal that acute administration of SF significantly decrease the duration of immo- 


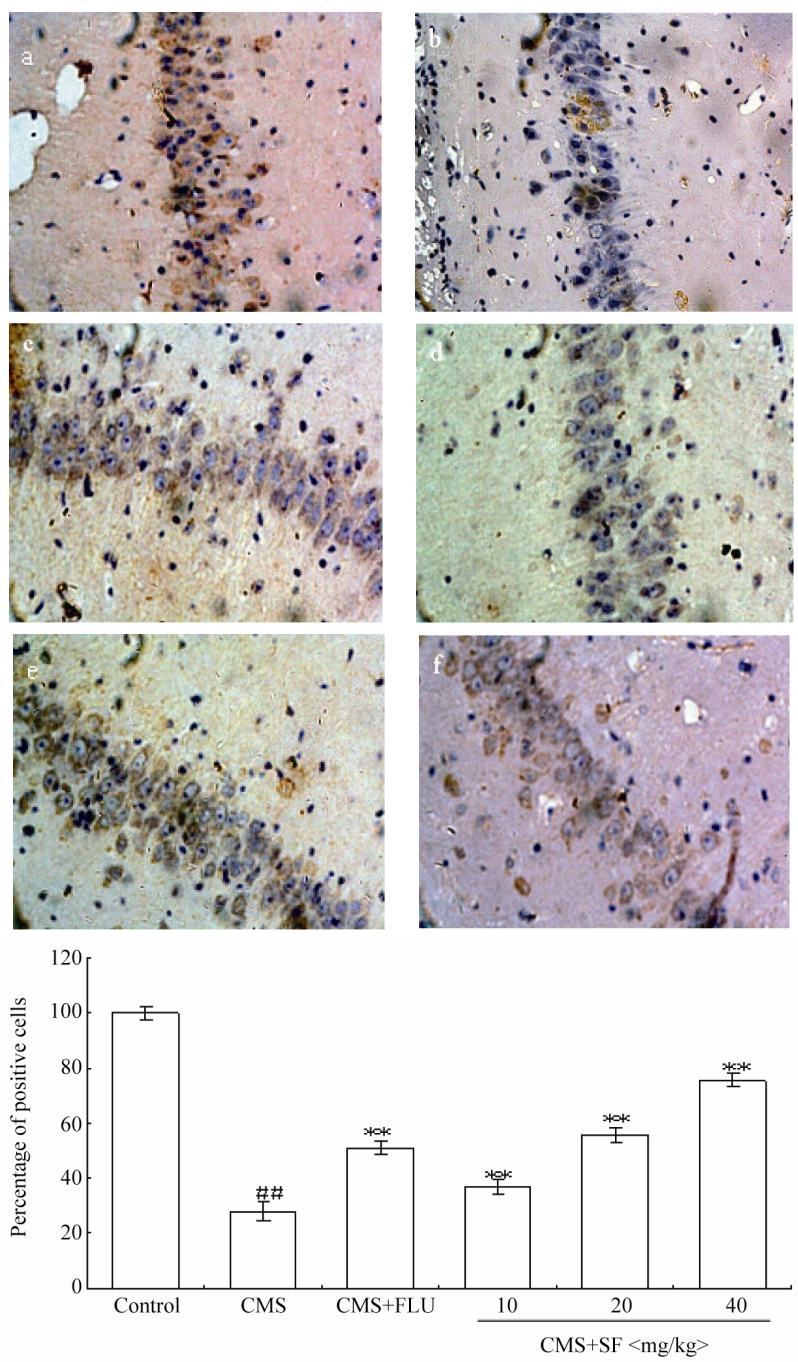

Figure 6. SF induces the proliferation of neural stem cell/ neural progenitor cells in the hippocampal CA3 sector of CMS-induced depression-like model rats $(\times 200)$.

a. Control; b. CMS; c. CMS + FLU(2.0 mg/kg/d); d. CMS + SF(10 mg/kg/d); e. CMS + SF (20 mg/kg/d); f. CMS + SF(40 mg/kg/d).

bility during forced-swimming test and tail-supension test in mice and rats, suggesting that SF has an acute antidepressant-like effect. However, SF has no any effects on reserpine-induced hypothermia, 5-HTP-induced head-twitch response, and potentiation of noradrenaline toxicity in mice, suggesting that the mechanisms of SF antidepressant-like effects are different from those of main kinds of antidepressants that have been employed in the treatment of depression for several decades. Longterm ip administration of SF reverses the effects of CMS on consumption of food and sucrose solution, weight gain, locomotion and exploration behavior, and significanly shortens the immobility time during forced-swimming test following CMS in rats, suggesting that SF has a chronic antidepressant-like effect [14].
The present results obtained from in vitro tests show that SF treatment promotes the proliferation of $\mathrm{PC} 12$ cells in the concentration range of $5-320 \mu \mathrm{mol} / \mathrm{L}$, and induce PC12 cells to differentiate to more mature cells with the morphological characteristics and molecular marker of neuronal-like cells. The present results obtained from in vivo tests show that SF treatment may upregulate the expressions of NGF and BDNF, and induce the proliferation of neural stem cell/neural progenitor cells in the hippocampi of CMS-induced depression-like model rats.

NGF is a well known characterized member of the neurotrophin family that stimulates differentiation, maintains phenotype, and ensures the survival of various populations of neurons in the central nervous system (CNS) $[34,35]$. The loss of NGF has been implicated in the loss of cholinergic tone and function [36-38]. Another neurotrophic factor, the BDNF, does not only promote neuronal survival anddifferentiation, but also regulates synaptic neurotransmission and plasticity in the CNS $[39,40]$. Furthermore, BDNF levels are increased in the hippocampal regions of mice and rats with access to exercise wheels and trophic factor gene therapy can ameliorate hippocampal deficits in monkey [41,42].

NGF and BDNF are responsible for the development, differentiation, maintenance and repair of neurons [4345]. Exogenous NGF rescues cholinergic neurons in the basal forebrain and improves cognitive function in impaired, aged or cholinergically lesioned animals [46-48]. A recent report shows that transplantation of fibroblasts genetically modified tosecrete NGF led to a slowing of cognitive decline in a Phase I clinical trial performed on patients suffering from mild Alzheimer's disease [49]. BDNF is highly present in the dentate gyrus and hippocampal CA3 sector, and to a lesser extent in the hippocampal CA1 sector [50]. It has been reported that the extent of dendritic arborization in the hippocampus was profoundly increased in BDNF transgenic mice compared to their control litter mates [51]. In BDNF gene knockout mice, furthermore, long-term potential (LTP) in the hippocampal CA1 region is severely reduced in hippocampal neurons and spatial learning is significantly impaired [52,53]. The results obtained from our experiments show that the hippocampal NGF and BDNF levels were obviously reduced in the CMS mice. Of interest is that SF treatment reversed the effects of CMS on the hippocampal NGF and BDNF levels in a dose-dependent manner. This finding suggests that SF-induced increases of the hippocampal NGF and BDNF levels may play a role in the antidepressant-like effect of SF.

The hippocampus is one of only a few brain regions where production of neurons occurs throughout the life time of animals, including humans [4]. Hippocampal 
neurogenesis can be influenced by several environmental factors and stimuli [54-57]. It has been shown that stressful experiences, including both physical and psychosocial stress, suppress the formation of hippocampal granule cells in a number of mammalian species [58-60]. Decreased cell proliferation has also been reported in response to both acute and chronic stress paradigms [61]. Importantly, it has been shown that chronic antidepressant treatment signicantly increases the number of BrdUlabeled cells in the dentate gyrus and hilus of the hippocampus. BrdU is incorporated into the newly synthesized DNA of S-phase cells and may provide an estimate for the fraction of cells in S-phase. A specific marker like BrdU is not only helpful for gaining further insights into the genesis of new neurons in the hippocampus, but also might be applicable to the development of strategies for therapeutic interventions [62]. Administration of several different classes of antidepressant, but not non-antidepressant, agents was found to increase BrdU-labeled cell number, indicating that this is a common and selective action of antidepressants [31]. Of interest is that the results obtained from our experiments show that administration of SF increase BrdU-labeled cell number in the hippocampi of CMS-induced depression-like model rats. This finding raise the possibility that increased cell proliferation and increased neuronal number induced by SF in CMS-induced depression-like model rats may be a mechanism by which SF treatment overwhelms the stressinduced atrophy and loss of hippocampal neurons.

\section{ACKNOWLEDGEMENTS}

The authors would like to thank Dr. Depu Yu for his great encouragement and continuous promotion.

\section{REFERENCES}

[1] Mao, Q.Q., Ip, S.P., Ko, K.M., Tsai, S.H., Zhao, M. and Che, C.T. (2009) Peony glycosides protect against corticos-terone-induced neurotoxicity in PC12 Cells. Cellular and Molecular Neurobiology, 29, 643-647. doi: 10.1007/s10571-009-9357-7

[2] Sapolsky, R.M. (2000) Glucocorticoids and hippocampal atrophy in neuropsychiatric disorders. Archives of General Psychiatry, 57, 925-935.

doi: 10.1001/archpsyc.57.10.925

[3] Magarinos, A.M., McEwen, B.S., Flugge, G. and Fuchs, E. (1996) Chronic psychosocial stress caused apical dendritic atrophy of hippocampal CA3 pyramidal neurons in subordinate tree shrews. The Journal of Neuroscience, 16, 3534-3540.

[4] Eriksson, P.S., Perfilieva, E., Björk-Eriksson, T., Alborn, A.M., Nordborg, C., Peterson, D.A. and Gage, F.H. (1998) Neurogenesis in the adult human hippocampus. Nature Medicine, 4, 1313-1317. doi:10.1038/3305

[5] Jacobs, B.L. (2002) Adult brain neurogenesis and de- pression. Brain, Behavior, and Immunity, 16, 602-609. doi:10.1016/S0889-1591(02)00015-6

[6] Ji, Y.B. (1999) Pharmacological action and application of blood-activating and stasis-eliminating available composition of traditional Chinese medicine. Heilongjiang Science and Technique Press, Harbin, 118-121.

[7] Jing, H., Yao, L.Y., Li, J.S., Song, Y.Q. and Chao, W. (2002) Research progress of pharmacology of sodium ferulate. Northwest Pharmaceutical Journal, 17, 236238.

[8] Grafe, E. (1992) Antioxidant potential of ferulic acid. Free Radical Biology and Medicine, 13, 435-448. doi:10.1016/0891-5849(92)90184-I

[9] Scott, B.C., Butler, J., Halliwell, B. and Aruoma, O.I. (1993) Evaluation of the antioxidant actions of ferulic acid and catechins. Free Radical Research, 19, 241-253. doi:10.3109/10715769309056512

[10] Fernandez, M.A., Saenz, M.T. and Garcia, M.D. (1998) Anti-inflammatory activity in rats and mice of phenolic acids isolated from Scrophularia frutescens. Journal of Pharmacy and Pharmacology, 50, 1183-1186. doi:10.1111/j.2042-7158.1998.tb03332.x

[11] Ozaki, Y. (1992) Antiinflammatory effect of tetramethylpyrazine and ferulic acid. Chemical \& Pharmaceutical Bulletin, 40, 954-956.

[12] Suzuki, A., Kagawa, D., Ochiai, R., Tokimitsu, I. and Saito, I. (2002a) Green coffee bean extract and its metabolites have a hypotensive effect in spontaneously hypertensive rats. Hypertension Research, 25, 99-107. doi:10.1291/hypres.25.99

[13] Suzuki, A., Kagawa, D., Fujii, A., Ochiai, R., Tokimitsu, I. and Saito, I. (2002b) Short- and long-term effects of ferulic acid on blood pressure in spontaneously hypertensive rats. American Journal of Hypertension, 15, 351357.

doi:10.1016/S0895-7061(01)02337-8

[14] Zhang, Y.P., Yu, L.J., Wang, Y.P., Liao, M.N., Ma, R.D., Zhang, X.Y. and Yu, T.X. (2011) Neuroprotective' effects of sodium ferulate and its antidepressant-like effect measured by acute and chronic experimental method in animal model of depression. Journal of Behavioral and Brain Science, 1, 37-46.

[15] Yu, T.X., Zhao, Y., Shi, W.C., Ma, R.D. and Yu, L.J. (1997) Effects of maternal oral administration of monosodium glutamate at a late stage of pregnancy on developing mouse fetal brain. Brain Research, 747, 195-206. doi:10.1016/S0006-8993(96)01181-X

[16] Yu, L.J., Zhang, Y.P., Ma, R.D., Bao, L., Fang, J.Z. and Yu, T.X. (2006) Potent protection of ferulic acid against excitotoxic effects of maternal intragastric administration of monosodium glutamate at a late stage of pregnancy on developing mouse fetal brain. European Neuropsychopharmacology, 16, 170-177. doi: 10.1016/j.euroneuro.2005.08.006

[17] Zhang, Y.P., Yu, L.J., Ma, R.D., Bao, L., Zeng, R., Fang, J.Z., Zhang, X.Y. and Yu, T.X. (2008a) Potent protective effect of ferulic acid on glutamate-induced neurotoxicity in adult mice. Chinese Journal of Neuromedicine, 7, 596599.

[18] Yang, P.P., Yu, L.J., Ma, R.D., Zhang, Y.P., Zhang, X.Y. and Yu, T.X. (2008) Intracerebroventricularly administered sodium ferulate-mediateed brain repair following 
glutamate-induced exitotoxic neuronal damage in adult mice. Chinese Journal of Behavioral Medical Science, 17, 13-15.

[19] Zhang, Y.P., Yu, L.J., Ma, R.D., Zhang, X.Y. and Yu, T.X. (2008b) Effects of administered sodium ferulate on the repair of glutamate-induced excitotoxic neuronal impair in mouse fetal brain. Chinise Journal of Behavioral Medical Science, 17, 968-971.

[20] Shafer, T.J. and Atchison, W.D. (1991) Transmitter, ion channel and receptor properties of pheochromocytoma (PC12) cells: A model for neurotoxicological studies. Neurotoxicology, 12, 473-492.

[21] Yoshizumi, M., Kogame, T., Suzaki, Y., Fujita, Y., Kyaw, M., Kirima, K., Ishizawa, K., Tsuchiya, K., Kagami, S. and Tamaki, T. (2002) Ebselen attenuates oxidative stress-induced apoptosis via the inhibition of the c-Jun $\mathrm{N}$-terminal kinase and activator protein-1 signalling pathway in PC12 cells. British Journal of Pharmacology, 136, 1023-1032.

doi:10.1038/sj.bjp.0704808

[22] Hansen, M.B., Nielsen, S.E. and Berq, K. (1989) Reexamination and further development of a precise and rapid dye method for measuring cell growth/cell kill. Journal of Immunological Methods, 119, 203-210. doi:10.1016/0022-1759(89)90397-9

[23] Dagai, L., Peri-Naor, R. and Birk, R.Z. (2009) Docosahexaenoic acid significantly stimulates immediate early response genes and neurite outgrowth. Neurochemical Research, 34, 867-75. doi:10.1007/s11064-008-9845-Z

[24] Julien J.P. and Mushynski W.E. (1998) Neurofilaments in health and disease. Progress in Nucleic Acid Research and Molecular Biology, 61, 1-23. doi: 10.1016/S0079-6603(08)60823-5

[25] Ali, H., Jurga, M., Kurgonaite, K., Forraz, N. and McGuckin, C. (2009) Defined serum-free culturing conditions for neural tissue engineering of human cord blood stem cells. Acta Neurobiologiae Experimentalis, 69, 1123.

[26] Guzen, F.P., De Almeida Leme, R.J., De Andrade, M.S., de Luca, B.A. and Chadi, G. (2009) Glial cell line- derived neuro-trophic factor added to a sciatic nerve fragment grafted in a spinal cord gap ameliorates motor impairments in rats and increases local axonal growth. Restorative Neurology and Neuroscience, 27, 1-16.

[27] Willner, P., Towell, A., Sampson, D., Sophokleous, S. and Muscat, R. (1987) Reduction of sucrose preference by chronic un- predictable mild stress, and its restoration by a tricyclic antidepressant. Psychopharmacology, 93, 358-364.

doi:10.1007/BF00187257

[28] Moreau, J.L., Jenck, F., Martin, J.R., Mortas, P. and Haefely, W.E. (1992) Antidepressant treatment prevents chronic unpredictabl mild stress-induced anhedonia as assessed by ventral tegmentum self-stimulation behavior in rats. European Neuropsychopharmacology, 2, 43-49. doi:10.1016/0924-977X(92)90035-7

[29] Shi, Z.R., Itzkowitz, S.H. and Kim, Y.S. (1988) A comparison of three immunoperoxidase techniques for antigen detection in colorectal carcinoma tissues. Journal of Histochemistry \& Cytochemistry, 36, 317-322. doi: 10.1177/36.3.3278057

[30] Chen, J.Q., Zhan, W.H., He, Y.L., Peng, J.S., Wang, J.P.,
Cai, S.R. and Ma, J.P. (2004) Expression of heparanase gene, CD44v6, MMP-7 and nm23 protein and their relationship with the invasion and metastasis of gastric carcinomas. World Journal of Gastroenterology, 10, 776782.

[31] Malberg, J.E., Eisch, A.J., Nestler, E.J. and Duman, R.S. (2000) Chronic antidepressant treatment increases neurogenesis in adult rat hippocampus. The Journal of Neuroscience, 20, 9104-9110.

[32] Parent, J., Yu, T., Leibowitz, R., Geschwind, D., Sloviter, R. and Lowenstein, D. (1977) Dentate granule cell neurogenesis is increased by seizures and contributes to aberrant net-work reorganization in the adult rat hippocampus. The Journal of Neuroscience, 17, 3727-3738.

[33] Paxinos, G. and Watson, C. (1986) The rat brain in stereo-taxic coordinates. Academic, San Diego.

[34] Ebendal, T. (1992) Function and evolution in the NG Ffamily and it sreceptors. Journal of Neuroscience Research, 32, 461-470. doi:10.1002/jnr.490320402

[35] Hefti, F., Knusel, B. and Lapchak, P.A. (1993) Protective effects of nerve growth factor and brain-derived neurotrophic factor on basal forebrain cholinergic neurons in adult rats with partial fimbrial transactions. Progress in Brain Research, 98, 257-263. doi: 10.1016/S0079-6123(08)62407-3

[36] Backman, C., Rose, G.M., Hoffer, B.J., Henry, M.A., Bartus, R.T., Friden, P. and Granholm, A.C. (1996) Systemic administration of nerve growth factor conjugate reverses age-related cognitive dysfunction and prevents cholinergic neuron atrophy. The Journal of Neuroscience, 16, 5437-5442.

[37] Isacson, O., Seo, H., Lin, L., Albeck, D. and Granholm, A.C. (2002) Alzheimer's disease and Down's syndrome: Roles of APP, tropic factors and Ach. Trends in Neurosciences, 25, 79-84. doi:10.1016/S0166-2236(02)02037-4

[38] Counts, S.E., Nadeem, M., Wuu, J., Ginsberg, S.D., Saragovi, H.U. and Mufson, E.J. (2004) Reduction of cortical Trk A but not p75 (NTR) protein in early-stage Alzheimer's disease. Annals of Neurology, 56, 520-531. doi:10.1002/ana.20233

[39] Lu, B. (2003) Pro-region of neurotrophins: Role in synaptic modulation. Neuron, 39, 735-738. doi:10.1016/S0896-6273(03)00538-5

[40] Suzuki, S., Numakawa, T., Shimazu, K., Koshimizu, H., Hara, T., Hatanaka, H., Mei, L., Liu, B. and Kojima, M. (2004) BDNF-induced recruitment of Trk B receptor into neuronal lipid rafts: Roles in synaptic modulation. The Journal of Cell Biology, 167, 1205-1215. doi: $10.1083 /$ jcb. 200404106

[41] Smith, D.E., Robers, J., Gage, F.H. and Tusynski, M.H. (1999) Age-associated neuronal atrophy occurs in the primate brain and is reversible by growth factor gene therapy. Proceedings of the National Academy Sciences of the United States of America, 96, 10893-10898. doi:10.1073/pnas.96.19.10893

[42] Cotman, C.W. and Berchtold, N.C. (2002) Exercise: A behavioral intervention to enhance brain health and plasticity. Trends in Neurosciences, 25, 295-301. doi:10.1016/S0166-2236(02)02143-4

[43] Bibel, M. and Barde,Y.A. (2000) Neurotrophins: Key 
regulators of cell fate and cell shape in the vertebrate nervous system. Genes \& Development, 14, 2919-2937. doi:10.1101/gad.841400

[44] Huang, E.J. and Reichardt, L.F. (2001) Neurotrophins: Roles in neuronal development and function. Annual Reviews of Neuroscience, 24, 677-736. doi: 10.1146/annurev.neuro.24.1.677

[45] Chao, M.V. (2003) Neurotrophins and their receptors: A convergene point for many signaling pathways. Nature Reviews Neuroscience, 4, 299-309. doi:10.1038/nrn1078

[46] Fischer, W., Wictorin, K., Bjorklund, A., Williams, L.R., Varon, S. and Gage, F.H. (1987) A melioration of cholinergic neuron atrophy and spatial memory impairment in aged rats by nerve growth factor. Nature, 329, 65-68. doi: $10.1038 / 329065 \mathrm{a} 0$

[47] Pizzo, D.P. and Thai, L.J. (2004) Intraparenchymal nerve growth factor improves behavioral deficits while minimizing the adverse effects of intracerebroventricular delivery. Neuroscience, 124, 743-755. doi:10.1016/j.neuroscience.2003.12.041

[48] Jakubowska-Dogru, E. and Gumusbas, U. (2005) Chronic in-tracerebroventricular NGF administration improves working memory in young adult memory deficientrats. Neuroscience Letters, 382, 45-50. doi: 10.1016/j.neulet.2005.02.059

[49] Tuszynski, M.H., Thal, L., Pay, M., Salmon, D.P., Bakay, R., Patel, P., Blesch, A., Vahlsing, H.L., Ho, G., Tong, G., Potkin, S.G., Fallon, J., Hansen, L., Mufson, E.J., Kordower, J.H., Gall, C. and Conner, J. (2005) A phase I clinical trial of nerve growth factor gene therapy for Alzheimer disease. Nature Medicine, 11, 551-555. doi:10.1038/nm1239

[50] Conner, J.M., Lauterborn, J.C., Yan, Q., Gall, C.M. and Varon, S. (1997) Distribution of brain-derived neurotrophic factor (BDNF) protein and mRNA in the normal adult CNS: Evident for anterograde axonal transport. The Journal of Neuroscience, 17, 2295-2313.

[51] Tolwani, R.J., Buckmaster, P.S., Varma, S., Cosgaya, J.M., Wu, Y., Suri, C. and Shooter, E.M. (2002) BDNF overexpression increases dendrite complexity in hippocampal dentate gyrus. Neuroscience, 114, 795-805. doi:10.1016/S0306-4522(02)00301-9

[52] Korte, M., Carroll, P., Wolf, E., Brem, G., Thoenen, H. and Bonhoeffer, T. (1995) Hippocampal long-term potentiation is impaired in mice lacking brain-derived neurotrophic factor. Proceedings of the National Academy Sciences of the United States of America, 92, 8856-8860. doi:10.1073/pnas.92.19.8856
[53] Linnarsson, S., Bjorklund, A. and Ernfors, P. (1997) Learning deficits in BDNF mutant mice. European Journal of Neuroscience, 9, 2518-2587. doi: 10.1111/j.1460-9568.1997.tb01687.x

[54] Kuhn, H.G., Dickinson-Anson, H. and Gage, F.H. (1996) Neuro-genesis in thedentate gyrus of the adult ratage-related decrease of neuronal progenitor proliferation. The Journal of Neuroscience, 16, 2027-2033.

[55] Kempermann, G., Kuhn, H.G. and Gage, F.H. (1997) More hip-pocampal neurons in adul tmice living in an enriched environment. Nature, 386, 493-495. doi: 10.1038/386493a0

[56] Gould, E., Beylin, A.,Tanapat, P., Reeves, A. and Shors, T.J. (1999) Learning enhances adult neurogenesis in the hippocam-pal formation. Nature Neuroscience, 2, 260265. doi.org/10.1038/6365

[57] Van Praag, H., Kempermann, G. and Gage, F. (1999) Running increases cell proliferation and neurogenesis in the adult mouse dentate gyrus. Nature Neuroscience, 2, 266-270. doi: $10.1038 / 6368$

[58] Gould, E., McEwen, B. S., Tanapat, P., Galea, L.A. and Fuchs, E. (1997) Neurogenesis in the dentate gyrus of the adult tree shrew is regulated by psychosocial stress and NMDA receptor activation. The Journal of Neuroscience, 17, 2492-2498.

[59] Gould, E., Tanapat, P., McEwen, B.S., Flugge, G. and Fuchs, E. (1998) Proliferation of granule cell precursors in the dentate gyrus of adult monkeys is diminished by stress. Proceedings of the National Academy Sciences of the United States of the America, 95, 3168-3171. doi:10.1073/pnas.95.6.3168

[60] Tanapat, P., Galea, L.A. and Gould, E. (1998) Stress inhibits the proliferation of granule cell precursors in the developing dentate gyrus. International Journal of Developmental Neuroscience, 16, 235-239. doi:0.1016/S0736-5748(98)00029-X

[61] Fuchs, E., Flugge, G., McEwen, B.S., Tanapat, P., Gould, E. (1997) Chronicsubordination stress inhibits neurogenesis and decreases the volume of the granule cell layer. Society Neurosci Abstr, 23, 317.

[62] Kee, N., Sivalingam, S., Boonstra, R. and Wojtowicz, J.M. (2002) The utility of Ki-67 and BrdU as proliferative markers of adult neurogenesis. Journal of Neuroscience Methods, 115, 97-105. doi:10.1016/S0165-0270(02)00007-9 